\title{
Attitudes of asthmatic and nonasthmatic children to physical exercise
}

\author{
This article was published in the following Dove Press journal: \\ Patient Preference and Adherence \\ 18 January 2013 \\ Number of times this article has been viewed
}

\author{
Vithleem Dimitrakaki' \\ Konstantinos Porpodis ${ }^{2}$ \\ Evangelos Bebetsos' \\ Paul Zarogoulidis ${ }^{2}$ \\ Antonis Papaiwannou ${ }^{2}$ \\ Theodora Tsiouda ${ }^{2}$ \\ Hlias Tsioulis ${ }^{2}$ \\ Konstantinos Zarogoulidis ${ }^{2}$ \\ 'Department of Physical Education \\ and Sport Science, Democritus \\ University of Thrace, Komotini, \\ Greece; 2Pulmonary Department, \\ G Papanikolaou General Hospital, \\ Aristotle University of Thessaloniki, \\ Thessaloniki, Greece
}

Purpose: The aim of this study was to examine the physical activity of children with and without asthma in Greece, the factors affecting their intention to exercise, and the influence of gender.

Method: The study involved 50 children with asthma and 50 children without asthma, aged 9-14-years old. We used the leisure time exercise questionnaire to assess the frequency and intensity of exercise. The planned behavior scale examined seven factors affecting physical activity: attitude, intention, self-identity, attitude strength, social role model, information, and knowledge.

Results: Asthmatic children did not differ significantly in mild, moderate, and overall level of physical activity from children without asthma but they participated less in intense and systematic exercise. The two asthmatic groups did not differ in any of the planned behavior factors. Significant differences between genders occurred with respect to self-identity and social role model. Boys appeared to exercise more regularly and intensely compared to girls.

Conclusion: Asthmatic children did not systematically participate in physical activity, preferring mostly mild and moderate intensity activities. Children with and without asthma had comparable positive attitudes and intentions toward exercise.

Keywords: planned behavior theory, asthma, sports, health behavior

Asthma constitutes the most frequent chronic disease during childhood. The disease is often hereditary and is usually presented (50-80\%) before the age of 5 years. ${ }^{1}$ It is also two to three times more frequent in boys than girls. ${ }^{2}$

According to the Global Initiative for Asthma, bronchial asthma is a chronic inflammatory disorder that is related to hyper responsiveness of the airways and leads to repeated episodes of wheezing, dyspnea, chest tightness, and cough, particularly at night or early in the morning. These episodes are usually associated with extensive but variable obstruction of air flow inside the lungs, which is often reversible, either spontaneously or after treatment. ${ }^{3}$

The most recent studies show a rising incidence of the disease, with the symptoms of asthma occurring in $12.7 \%$ in school age children. ${ }^{4}$ Greece has the lowest prevalence of childhood asthma compared to Mediterranean and European countries. ${ }^{5}$

Chronic asthma affects parents, school systems, communities, and health care providers and is associated with many childhood problems that lead to an overall decreased quality of life. Dealing with asthmatic symptoms of school age children has been linked to depression and anxiety in children. ${ }^{6}$ Although asthma has no existing cure, the disease can be well managed. Part of the therapeutic formula of asthma, especially in children and adolescents, includes exercise. ${ }^{7}$
Correspondence: Paul Zarogoulidis G Papanikolaou General Hospital, Aristotle University of Thessaloniki, Thessaloniki, Exohi 57010, Greece Tel +306977271974

Fax +302310992433

Email pzarog@hotmail.com 
Although historically participation in exercise was discouraged, current guidelines emphasize safe exercise in young asthmatic patients. Exercise is indicated to help decrease the incidence and severity of the disease and to improve the overall quality of life. ${ }^{8}$ Therefore, patients with asthma should not be distinguished from the general population in any area of human activity. ${ }^{9}$ Regular exercise provides many physical and psychosocial benefits to children with asthma. It increases aerobic ability, muscular strength, and other attributes of the physical condition. ${ }^{10}$ Pulmonary function can be positively influenced ${ }^{11}$ and dyspnea can be significantly reduced. ${ }^{12}$ The psychosocial benefits of exercising reported by children were enjoyment, socialization, self-confidence, energy, increased athletic performance, and relaxation. ${ }^{13}$

The incidence of bronchospasm and the possibility of asthma exacerbation after exercise (exercise-induced asthma) prevent many children from participating in physical activities. ${ }^{14}$ In addition, unpleasant past experiences regarding the exercise may result in avoidance of physical activity, leading to a sedentary lifestyle. ${ }^{15}$

Limited physical activity also constitutes a risk factor for childhood asthma and has been associated with increased incidence of asthma in adolescence. ${ }^{16}$ The effect of inactivity is direct and can cause stenosis of the airways by reducing the distensibility of the smooth muscles of bronchi. ${ }^{17} \mathrm{~A}$ recent study showed that bronchial hyper responsiveness in children with asthma increases when the hours of exercise per week decrease, ${ }^{16}$ and the majority of studies support the relationship between asthma and decreased involvement in physical activities among school-aged children. ${ }^{18-20}$ Children and adolescents with asthma showed reduced exercise tolerance compared to their healthy peers, and limited participation has been attributed to their disease. ${ }^{21,22}$

Only a few studies have been carried out comparing activity levels between asthmatic children and their unaffected peers. ${ }^{23,24}$ In a study from Taiwan, both groups were similar in moderate to vigorous physical activity, although asthmatic children participated less in vigorous activities than their nonasthmatic counterparts. ${ }^{25}$ Interestingly, one study showed that children with asthma exercised more and preferred more intense activities compared to their nonasthmatic peers. ${ }^{26}$

Many studies have taken into account the importance of physical activity in health promotion and have focused on the approach and process of decision making in exercise participation. The findings identified factors such as attitudes, motivation, self-control, self-efficacy, and enjoyment in physical activity. ${ }^{27}$ Record and evaluation of psychological factors that influence children's health behavior was based on one of the most famous theoretical models - the planned behavior theory. ${ }^{28}$

The theory of planned behavior was developed by Ajzen and Fishbein ${ }^{29}$ and is one of the most commonly used theories of the relationship between attitude and behavior. According to this theory, as the intention of an individual increases, the possibility of performing the behavior increases.

The most important factors of the theory in predicting a person's intention to participate in a particular activity are: (a) attitudes, the degree of positive or negative response toward the behavior; (b) intention, precedes each behavior and determines whether or not it will happen; (c) social role model, the role that individuals of the social environment play in the execution of the behavior; (d) attitude strength, the certainty that everyone feels in order to participate in the activity; (e) self-identity, focuses on how capable each child considers himself/herself in order to participate in the activity; (f) information, information on matters related to the behavior; and $(\mathrm{g})$ knowledge, education on matters related to the behavior. ${ }^{28-31}$

The development of attitudes and behaviors toward exercise can increase children's participation in exercise, contributing to mental and physical health, better management of the disease, prevention of complications, and delay of disease development. ${ }^{32}$ Asthmatic children who experience the benefits of exercise are more likely to be active throughout their lives. However, there is limited research focusing on attitudes toward exercise from the perspective of school-aged children with asthma. Attitudes toward exercise and perceived physical activity competence of these children have been significantly correlated to physical activity involvement, ${ }^{15}$ but no behavioral differences toward exercise, self-perception, or physical self-concepts have been found between asthmatic and nonasthmatic children. ${ }^{23}$ More studies are needed to investigate whether children with asthma exercise less than their healthy peers and to what extent they incorporate the psychological factors related to physical activity.

In the present research we use the theory of planned behavior to address, for the first time, factors of attitude and intent to exercise in the asthmatic population. New information will emerge from this research regarding the level of physical activity of children with and without asthma in Greece. The understanding of how children perceive their participation in recreational sporting activities and what factors influence their attitude and will contribute to identifying strategies that increase their participation in exercise and provide health promotion intervention in school settings. 
The purpose of the research was to examine the level of physical activity in children with and without asthma, to investigate the factors of the theory of planned behavior that affect their intention to exercise, and to investigate the effect of gender in the above factors.

\section{Materials and methods Sample}

The study included 50 children with asthma and 50 without asthma. Of these 100 children, 42 were boys and 58 were girls and all were aged between 9 and 14 years (mean \pm standard deviation, $11.44 \pm 1.33$; Tables 1 and 2). We used random and convenience sampling; participation was voluntary. The children were allocated to the asthma group based on whether they had been informed by a doctor that they had asthma. In order to collect a sufficient sample of children with asthma, recruitment was carried out in pediatric/pulmonary clinics that the children visited for their pre-arranged examination. Children were excluded if they were prohibited from exercising or had to abstain from their usual physical activity from, for example, illness, recent injuries, weather conditions, or school exam period.

\section{Instruments}

Leisure time exercise questionnaire. The leisure time exercise questionnaire was designed in order to evaluate the frequency and intensity of exercise at leisure time over a 7-day period. ${ }^{33}$ It is a reliable and valid instrument for measuring physical activity even in children as young as 9 - to 10 -years old. ${ }^{34}$ Thedorakis and Hassandra standardized the questionnaire for the Greek population. ${ }^{35}$

The first part of the questionnaire measures weekly frequencies of physical activity in three intensity categories based on the subjective perception of each participant: intense (the average value of metabolic equivalents of task [MET] for this category of physical activity is 9 METs), moderate (average value 5 METs), and mild (average value 3 METs). In the second part, the participants provided information regarding how often they participated in a sweaty, systematic, physical activity during a 7 -day period.

The overall indicator of exercise or the total energy cost is calculated by the sum of the number of the frequency

Table I Distribution of the sample by gender and group

\begin{tabular}{llll}
\hline & Asthma & Without asthma & Total \\
\hline Boys & 19 & 23 & 42 \\
Girls & 31 & 27 & 58 \\
Total & 50 & 50 & 100 \\
\hline
\end{tabular}

Table 2 Mean and standard deviations of age by gender and group

\begin{tabular}{|c|c|c|c|c|}
\hline & \multicolumn{4}{|l|}{$M \pm S D$} \\
\hline & Boys & Girls & Without asthma & Asthma \\
\hline Age & $11.52 \pm 1.29$ & $11.36 \pm 1.37$ & $\mid 1.52 \pm 1.31$ & $11.34 \pm 1.36$ \\
\hline
\end{tabular}

of activities per category, multiplied by their respective averages of the value of energy cost (MET) per category: (intense exercise $\times 9$ METs + moderate exercise $\times 5$ METs + mild exercise $\times 3$ METs). MET is a simple way of calculating the energy expenditure for any activity. ${ }^{33}$ One MET is equivalent to a metabolic rate consuming 1 calorie $/ \mathrm{kg}$ of body weight per 60 minutes of specific physical activity.

Planned behavior questionnaire. The questionnaire of Ajzen and Madden includes 33 questions and consists of the following seven factors: ${ }^{36}$

1. Attitudes (six questions), for example, "For me to exercise regularly the next 2 months is ..." Responses were rated on a 7-point scale on six bipolar adjectives $(7=\operatorname{good}$ to $1=$ bad, $7=$ healthy to $1=$ unhealthy, etc).

2. Intention (three questions), for example, "I intend to exercise regularly the next 2 months." Responses were rated on a 7 -point scale where $1=$ very unlikely and $7=$ very likely.

3. Social role model (four questions), for example, "Generally, I enjoy doing what some important individuals want me to do." Responses were given on a 7-point scale where $1=$ will strongly disagree and $7=$ will strongly agree.

4. Self-identity (four questions), for example, "It is in my character to exercise regularly the next 2 months." Responses were given on a 7-point scale where $1=$ strongly disagree and $7=$ strongly agree.

5. Attitude strength (eight questions), for example, "Is it right for you to exercise regularly for the next 2 months?" Responses were rated on a 7-point scale where $7=$ not at all and $1=$ very much so.

6. Information (four questions), for example, "I am very interested in any information regarding exercising regularly." Responses were given on 7-point scale where $1=$ I strongly disagree and 7 = I strongly agree.

7. Knowledge (four questions), for example, "How well informed about exercising regularly do you believe that you are?" The answers were rated on 7-point scale where $7=$ very little and $7=\mathrm{a}$ lot.

\section{Procedure}

Data were collected in cultural societies and pediatric/ pulmonary clinics of northern Greece. The participants 
completed two questionnaires: the leisure time exercise questionnaire 33,35 and the planned behavior questionnaire..$^{30,36,37}$ Personal information and questions regarding classification and exclusion criteria were also included.

The children and their parents were informed about the procedure, and the parents gave their permission. The questionnaires were anonymous, and the children answered without parental assistance. All procedures were performed in compliance with relevant laws and institutional guidelines and were approved by the Democritus University of Thrace's Ethics Committee.

\section{Statistical analysis}

The analysis of reliability of Cronbach $\alpha$ was used for the internal consistency of the scales. Two-way analysis of variance (ANOVA), with group and gender, was used for each of the 13 dependent variables of the study.

\section{Results}

Of the 100 study participants, seven children were excluded from the research for not taking part in their usual physical activity due to illness, injuries, or travelling. The results from the descriptive analysis of the planned behavior factors and the physical activity factors are presented in Table 3.

\section{Analysis of reliability}

For the planned behavior questionnaire, internal consistency was verified by calculating the coefficient of Cronbach $\alpha$. The coefficient for each questionnaire factor was: attitudes $\alpha=0.87$, intention $\alpha=0.99$, self-identity $\alpha=0.92$, attitudes strength $\alpha=0.94$, social role model $\alpha=0.62$, information $\alpha=0.84$, and knowledge $\alpha=0.97$. The overall internal consistency of the scale was $\alpha=0.97$.

The leisure time exercise questionnaire has previously been assessed for its reliability by using the test-retest method. This revealed high validity and reliability in children and adolescents $(r=0.81 ; P<0.001) .{ }^{33}$

\section{ANOVA}

Differences by group. For frequency and level of physical activity, there were significant differences among the groups in the variable intense exercise $\left(F_{(1.96)}=4.749 ; P<0.05\right)$ and in systematic exercise $\left(F_{(1.96)}=5.471 ; P<0.05\right)$. Children without asthma had more intense (mean score \pm standard deviation, $3.66 \pm 2.02)$ and more systematic exercise $(2.48 \pm 0.73)$ than asthmatic children $(2.78 \pm 1.95$ and $2.08 \pm 0.82$, respectively) (Figure 1 ). There were no significant differences among groups with moderate or mild exercise, total exercise indicator, or planned behaviors.

Differences by gender. Physical activity by gender was found to be significantly different in intense exercise $\left(F_{(1.96)}=7.379\right.$; $P<0.01)$, mild exercise $\left(F_{(1.96)}=8.232 ; P<0.01\right)$, total exercise indicator $\left(F_{(1.96)}=20.043 ; P<0.01\right)$, and systematic exercise $\left(F_{(1.96)}=4.960 ; P<0.05\right)$. The mean scores of boys (intense exercise, $3.88 \pm 2.06$; mild exercise, $4.93 \pm 2.86$; total exercise indicator, $68.29 \pm 18.31$; systematic exercise, $2.5 \pm 0.77$ ) were higher than those of girls (intense exercise, $2.74 \pm 1.87$; mild exercise, $3.45 \pm 2.54$; total exercise indicator, 52.86 \pm 15.17; systematic exercise, 2.12 \pm 0.79 ) (Figures 2 and 3 ).

Factors of planned behavior by gender were significantly different only for self-identity $\left(F_{(1.96)}=4.429 ; P<0.05\right)$ and social role model $\left(F_{(1.96)}=4.988 ; P<0.05\right)$. For self-identity,

Table 3 Mean scores, standard deviations, and statistical significances of the physical activity and planned behavior variables by gender and group

\begin{tabular}{lllll}
\hline & M SD & & & \\
\cline { 2 - 5 } & Boys & Girls & Without asthma & Asthma \\
\hline Intense exercise & $3.88^{* *} \pm 2.06$ & $2.74^{* *} \pm 1.87$ & $3.66^{*} \pm 2.02$ & $2.78^{*} \pm 1.95$ \\
Moderate exercise & $3.90 \pm 1.52$ & $3.57 \pm 1.74$ & $3.66 \pm 1.82$ & $3.76 \pm 1.49$ \\
Mild exercise & $4.93^{* *} \pm 2.86$ & $3.45^{* *} \pm 2.54$ & $3.74 \pm 2.85$ & $4.40 \pm 2.61$ \\
Total exercise indicator & $68.29 * * \pm 18.31$ & $52.86^{* *} \pm 15.17$ & $62.06 \pm 18.43$ & $56.62 \pm 17.66$ \\
Systematic physical activity & $2.5 * \pm 0.77$ & $2.12^{*} \pm 0.79$ & $2.48^{*} \pm 0.73$ & $2.08^{*} \pm 0.82$ \\
Attitudes & $6.8 I \pm 0.28$ & $6.69 \pm 0.31$ & $6.77 \pm 0.27$ & $6.71 \pm 0.34$ \\
Intention & $6.65 \pm 0.76$ & $6.36 \pm 0.74$ & $6.60 \pm 0.73$ & $6.37 \pm 0.78$ \\
Self-identity & $6.41 * \pm 1.01$ & $5.97 * \pm 0.92$ & $6.29 \pm 0.97$ & $6.03 \pm 0.98$ \\
Attitudes strength & $6.59 \pm 0.73$ & $6.26 \pm 0.88$ & $6.47 \pm 0.78$ & $6.33 \pm 0.88$ \\
Social role model & $6.39 * \pm 0.54$ & $6.59 * \pm 0.40$ & $6.55 \pm 0.45$ & $6.47 \pm 0.49$ \\
Information & $5.41 \pm 0.91$ & $5.13 \pm 0.74$ & $5.34 \pm 0.84$ & $5.16 \pm 0.80$ \\
Knowledge & $5.86 \pm 1.10$ & $5.51 \pm 0.76$ & $5.6 \pm 1.02$ & $5.67 \pm 0.85$ \\
\hline
\end{tabular}

Notes: $* P<0.05 ; * * p<0.01$.

Abbreviation: SD, standard deviation. 


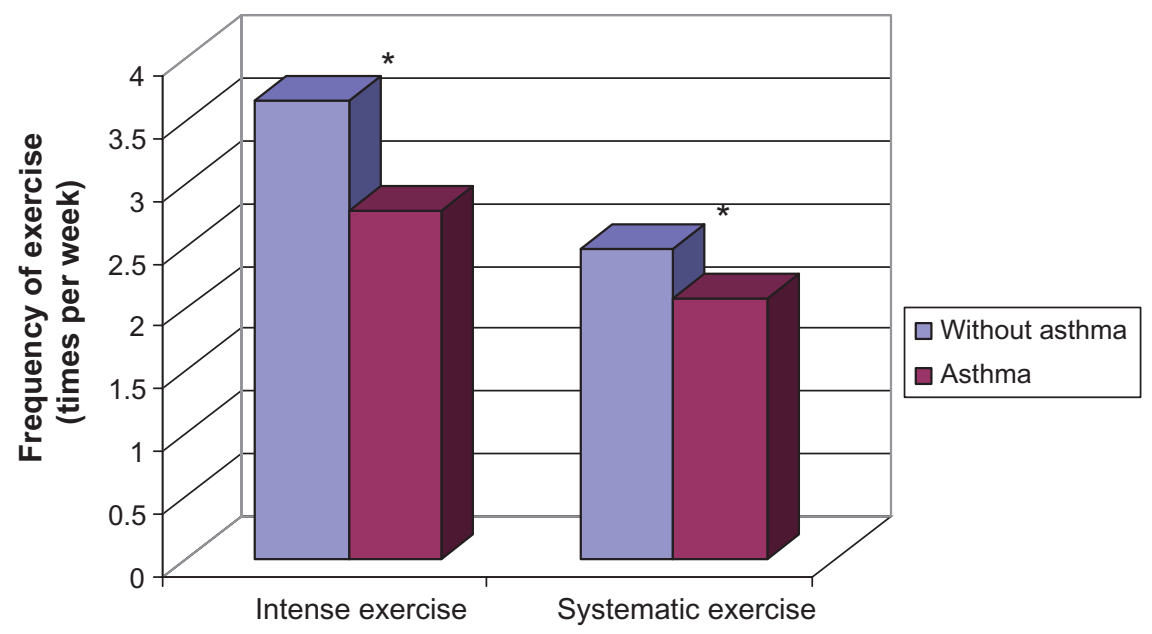

Figure I Significant differences among children with and without asthma in intense and systematic exercise. Note: $* P<0.05$.

the mean score of boys $(6.41 \pm 1.01)$ was higher than that of girls $(5.97 \pm 0.92)$, while the opposite was found for social role model of girls $(6.59 \pm 0.4)$ and boys $(6.39 \pm 0.54)$ (Figure 4).

Interaction of gender and group factor. No interaction was found between gender and any of the 13 variables of the study.

\section{Discussion}

Our results confirmed previously published findings in which no significant differences were found in mild or moderate exercise or the overall level of physical activity between asthmatic children and their nonasthmatic peers. ${ }^{15,38}$ These findings suggest that children with and without asthma have a comparable level of physical activity. The reasons for this could be that (1) children, especially those with mild asthma, underestimate their symptoms or even ignore them or (2) health education at school and physicians' recommendations to participate in all physical activity may have influenced the children with asthma to lead normal, physically active lives.

Our results also showed that children with asthma had lower levels of intense exercise and limited systematic physical activity compared to their nonasthmatic counterparts. Our results are in agreement with other recent studies in which asthma was shown to negatively affect systematic exercise involvement of children, particularly in intense and extended activities. ${ }^{14,25}$ These behaviors suggest that asthmatic children are influenced by factors associated with the disease to avoid intense and regular activity, eg, greater sense of

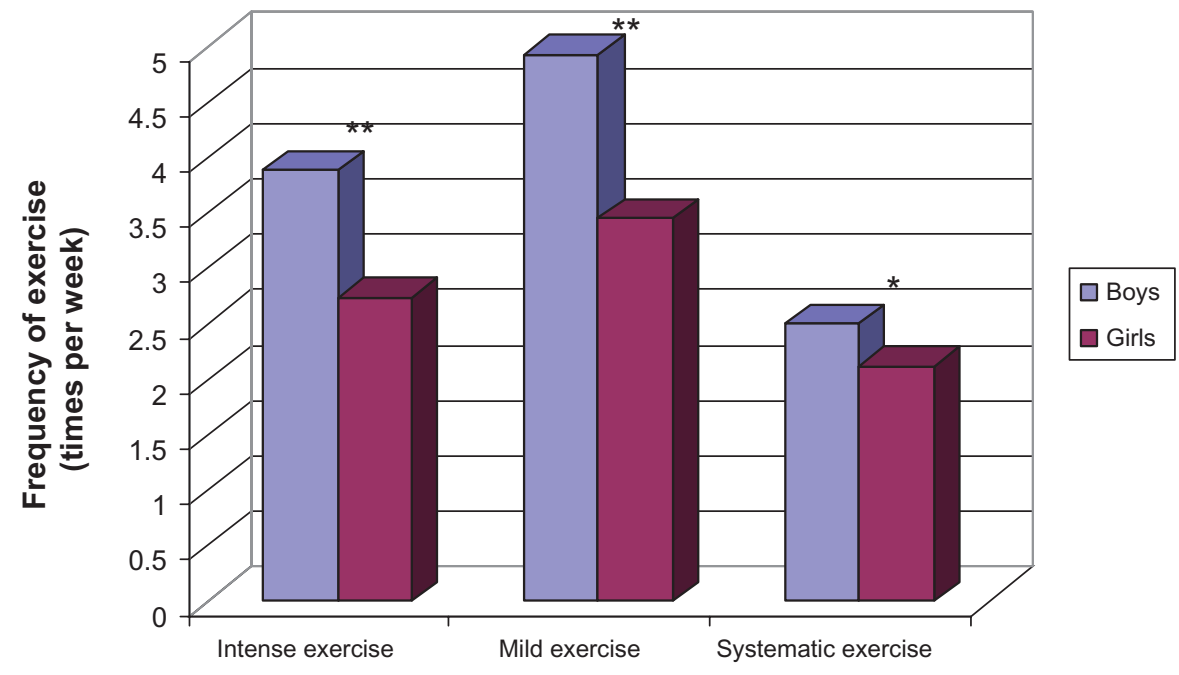

Figure 2 Differences between boys and girls in the variables of physical activity. Notes: $* p<0.05 ; * * p<0.01$. 


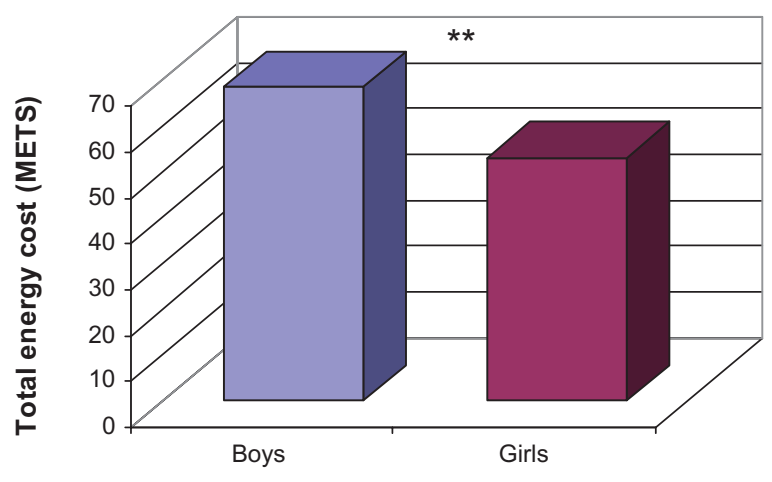

Figure 3 Differences between boys and girls in the total exercise indicator. Note: $* * p<0.01$.

Abbreviation: METS, metabolic equivalents of task.

their disability. The removal of the barriers responsible for this behavioral pattern may help modify attitudes among school-age asthmatic children toward a particular level of exercise (from mild/moderate to more intense).

Our investigation of the seven planned behavior factors for exercise did not show any significant differences between asthmatic and nonasthmatic children, which is in agreement with the findings of Brook and colleagues. ${ }^{39}$ Children with and without asthma appeared to have equivalent positive attitudes and intentions toward physical activity and were similarly informed regarding exercise issues. Although some levels of physical activity differed between the two groups, attitudinal factors did not differ, possibly because affected children had (as expressed in the questionnaire) a strong desire to be treated as healthy youngsters and live normal lives.

Factors that showed a significant difference between genders were self-identity and social role model. Boys/girls considered themselves more capable of participating in exercise, while exercise participation by girls was influenced more by individuals in their social environment. The effect of gender on these two factors has been noted in other studies. Factors of perceived competence and commitment to physical education have been reported as adversely affecting the intent of girls to participate in physical activity, ${ }^{40}$ while the opinion and support of social peers appeared to more positively influence involvement in physical activity of girls compared to boys. ${ }^{41}$ Gender differences in all the physical activity factors, except moderate exercise, confirmed the results of other studies that girls participate less in sports than boys and express less interest for future involvement. ${ }^{42,43}$ The difference between genders in physical activity becomes more evident as children approach puberty and inactivity mechanisms activate in girls. ${ }^{44}$

It is worth mentioning that despite our findings in gender differences, the results did not reveal any interaction with asthma. This can be attributed to the fact that we did not classify the severity of asthma. If the asthmatic sample had a high proportion of mild asthma, this may have eliminated the differences between the two groups and the interaction between asthma and gender. A previous study between healthy controls and affected children also showed that childhood asthma is not associated with a decreased level of daily physical activity. ${ }^{38}$ The classification of participants into asthma severity groups could be included by using the diagnosis of a specialized practitioner during sampling or assessing the symptoms of asthma with an approved questionnaire.

Another limitation to our study that should also be addressed is the assessment of physical activity. Self-report questionnaires are widely criticized as possibly not reflecting the real level of physical activity. For this reason, researchers have suggested that physicians should obtain reports from children rather than parents. ${ }^{45} \mathrm{La}$ Torre et al argued that

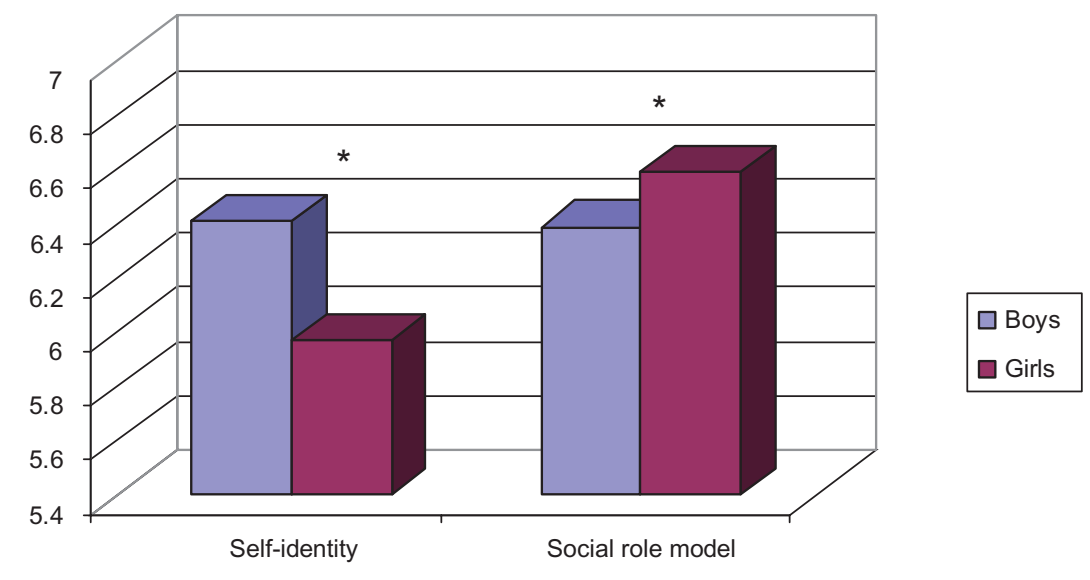

Figure 4 Differences between boys and girls in self-identity and social role model factors. Note: $* P<0.05$. 
using self-reports is more appropriate than using objective instrument measurements. ${ }^{46}$ We tried to address this limitation by selecting an instrument appropriate for children and excluding parental involvement.

Health professionals and physical education teachers should motivate all children, especially those with asthma, to increase their level and frequency of physical activity. Future health promotion interventions should target school settings so that exercise is part of the normal lifestyle. The publicity about exercise and an athletic lifestyle, relevant campaigns, education and information on exercise and health issues, promotion of interventional or experiential exercise programs, and a permanent political health education program should constitute a priority for our country.

\section{Conclusion}

Our findings suggest that children with and without asthma have the same positive attitudes and intentions toward physical activity. The two groups participated similarly in mild/moderate intensity activities, but asthmatic children did not exercise regularly, having the tendency to avoid more intense activities.

Future research should investigate the impact of psychological factors on the behavior of children with asthma toward physical activity. This could provide more information on whether these children require special treatment by physical education teachers, particularly in terms of motivation.

\section{Disclosure}

The authors report no conflicts of interest in this work.

\section{References}

1. National Institutes of Health (NIH). National Asthma Education and Prevention Program. Expert Panel Report III: Guidelines for the Diagnosis and Management of Asthma. Bethesda, MD: National Institutes of Health; National Heart, Lung, and Blood Institute; 2007. NIH Publication No $07-4051$.

2. Moffatt MF, Gut IG, Demenais F, Strachan DP, Bouzigon E, Heath S, et al; Gabriel Consortium. A large-scale, consortium-based genomewide association study of asthma. N Engl J Med. 2010;363:1211-1221.

3. Global Initiative for Asthma (GINA). Guidelines: GINA Report, Global Strategy for Asthma Management and Prevention. Available from: http:// www.ginasthma.org/uploads/users/files/WorldAsthmaDayBkgrdr2012. pdf. Accessed October 16, 2011.

4. Centers for Disease Control and Prevention. State of childhood asthma, United States: 1980-2005. 2006. Available from: http://www.cdc.gov/ nchs/pressroom/06facts/asthma1980-2005.htm. Accessed February 16, 2012.

5. The International Study of Asthma and Allergies in Childhood (ISAAC) Steering Committee. Worldwide variations in the prevalence of asthma symptoms. Eur Respir J. 1998;12:315-335.

6. Clayton S. Pediatric asthma: overcoming barriers to an improved quality of life. Br J Nurs. 2005;14(2):80-85.

7. Bateman ED, Hurd SS, Barnes PJ, Bousquet J, Drazen JM, FitzGerald M, et al. Global strategy for asthma management and prevention: GINA executive summary. Eur Respir J. 2008;31(1):143-178.
8. Wirrell E, Cheung C, Spier S. How do teens view the physical and social impact of asthma compared to other chronic diseases? J Asthma. 2006;43:155-160.

9. Sidiropoulou M, Fotiadou E, Tsimaras V, Dokas A, AggelopoulouSakadami N. The effect of applying intermittent training in children with exercise induced asthma. Pediatric of Northern Greece. 2003; 15(4):341-348.

10. Counil FP, Varray A, Matecki S, et al. Training of aerobic and anaerobic fitness in children with asthma. J Pediatr. 2003;142:179-184.

11. Charitopoulos K, Beneka A, Malliou P, Godolias G. Swimming for asthmatic children: Basic training principles to improve their quality of life. Inquiries in Sport and Physical Education. 2003;1(2):184-188. Greek.

12. Ram FSF, Robinson S, Black PN, Picot J. Physical training for asthma [review]. Cochrane Database Syst Rev. 2005;4:CD001116.

13. O'dea JA. Why do kids eat healthful food? Perceived benefits of and barriers to healthful eating and physical activity among children and adolescents. J Am Diet Assoc. 2003;103(4):497-501.

14. Firrincieli V, Keller A, Ehrensberger R, et al. Decreased physical activity among head start children with a history of wheezing: use of an accelerometer to measure activity. Pediatr Pulmonol. 2005;40:57-63.

15. Pianosi PT, Davis HS. Determinants of physical fitness in children with asthma. Pediatrics. 2004;113(3):225-229.

16. Rasmussen F, Lambrechtsen J, Siersted HC, Hansen HS, Hansen NC. Low physical fitness in childhood associated with the development of asthma in young adulthood: the Odense schoolchild study. Eur Respir J. 2000; 16:866-870.

17. Philpott J, Houghton K, Luke A. Physical activity recommendations for children with specific chronic health conditions: Juvenile idiopathic arthritis, hemophilia, asthma and cystic fibrosis. Paediatr Child Health. 2010;15(4):213-218.

18. Lang DM, Butz AM, Duggan AK, Serwint JR. Physical activity in urban school-aged children with asthma. Pediatrics. 2004;113(4): 341-346.

19. Mansour ME, Lanphear BP, DeWitt TG. Barriers to asthma care in urban children: parent perspectives. Pediatrics. 2000;106(3): 512-519.

20. Jones SE, Merkle SL, Fulton JE, Wheeler LS, Mannino DM. Relationship between asthma, overweight, and physical activity among US high school students. J Community Health. 2006;31(6):469-478.

21. Basaran S, Guler-Uysal F, Ergen N, Seydaoglu G, Bingol-Karakoç G, Ufuk Altintas D. Effects of physical exercise on quality of life, exercise capacity and pulmonary function in children with asthma. $J$ Rehabil Med. 2006;38(2):130-135.

22. Welsh L, Kemp JG, Roberts RG. Effects of physical conditioning on children and adolescents with asthma. Sports Med. 2005;35(2):127-141.

23. Nystad W. The physical activity level in children with asthma based on a survey among 7-16 year old school children. Scand J Med Sci Sports. 1997;7:331-335.

24. Chen Y, Dales R, Krewskim D. Leisure-time energy expenditure in asthmatics and non-asthmatics. Respir Med. 2001;95(1):13-18.

25. Chiang LC, Huang JL, Fu LS. Physical activity and physical selfconcept: comparison between children with and without asthma. $J A d v$ Nurs. 2006;54:653-662.

26. Ravens-Sieberer U, Gerharz E, Wieselberger M, Eiser C, Bullinger M. News from the play-ground. Is Quality of life measurable in children? Br J Urol. 1999;35:123-134.

27. Kohl HW, Hobbs KE. Development of physical activity behaviors among children and adolescents. Pediatr. 1998;101:549-554.

28. Ajzen I. The theory of planned behavior. Organ Behav Hum Decis Process. 1991;50:179-211.

29. Ajzen I, Fishbein M. Understanding Attitudes and Predicting Social Behaviour. Englewood Cliffs, NJ: Prentice-Hall; 1980.

30. Theodorakis Y. Planned behaviour, attitude strength, role-identity, and the prediction of exercise behavior. Sport Psychol. 1994;8:149-165.

31. Tsigilis N, Koustelios A, Theodorakis Y. The role of knowledge and information in predicting exercise participation: an extension of planned behavior model. Int J Phys Educ. 2007;4:143-153. 
32. Welsh L, Roberts RGD, Kemp JG. Fitness and physical activity in children with asthma. Sports Med. 2004;34:861-870.

33. Godin G, Shephard RJ. A simple method to assess exercise behaviour in the community. Can J Appl Sport Sci. 1985;10:141-146.

34. Sallis JF, Buono MJ, Roby JJ, Micale FG, Nelson JA. Seven-day recall and other physical activity self-reports in children and adolescents. Med Sci Sports Exercise. 1993;25(1):99-108.

35. Theodorakis Y, Hassandra M. Smoking and exercise, Part 2: Differences between trainees and non-trainees. Inquiries in Sport and Physical Education. 2005;3(3):239-248. http://www.academia.edu/1117547/ Morningness-eveningness_and_physical_activity_in_adolescents.

36. Ajzen I, Madden TJ. Predictions of goal-directed behaviour: Attitudes, intentions and perceived behavioural control. J Exp Soc Psychol. 1986;22:453-457.

37. Bebetsos E, Theodorakis I, Chroni S. Predictive factors of the intention to exercise and healthy nutrition. Physical Activity and Quality of Life. 2001;2:13-20. Greek.

38. van Gent R, van der Ent CK, van Essen LEM, Rovers MM, Kimpen JLL, de Meer G, et al. No differences in physical activity in (un)diagnosed asthma and healthy controls. Pediatr Pulmonol. 2007;42:1018-1023.

39. Brook U, Stein D, Alkalay Y. The attitude of asthmatic and nonasthmatic adolescents toward gymnastic lessons at school. J Asthma. 1994;31(3):171-175.
40. Belcher D, Lee AM, Solmon MA, Harrison L. The influence of genderrelated beliefs and conceptions of ability on learning the hockey wrist shot. Res Q Exerc Spor. 2003;74:183-192.

41. Sallis JF, Berry CC, Broyles SL, McKenzie TL, Nader PR. Variability and tracking of physical activity over $2 \mathrm{yr}$ in young children. Med Sci Sports Exerc. 1995;27(7):1042-1049.

42. Trost SG, Pate RR, Sallis JF, Freedson PS, Taylor WC, Dowda M, et al. Age and gender differences in objectively measured physical activity in youth. Med Sci Sports Exerc. 2002;34(2):350-355.

43. Vu M, Murrie D, Gonzalez V, Jobe J. Listening to girls and boys talk about girls' physical activity behaviors. Health Educ Behav. 2006;33(1):81-96.

44. Goran MI, Gower BA, Nagy TR, Johnson R. Developmental changes in energy expenditure and physical activity in children: Evidence for a decline in physical activity in girls prior to puberty. Pediatr. 1998;101:887-891.

45. Panditi S, Silverman M. Perception of exercise induced asthma by children and their parents. Arch Dis Child. 2003;88(9):807-811.

46. La Torre G, Masala D, De Vito E, Langiano E, Capelli, Ricciardi W. Extra-curricular physical activity and socioeconomic status in Italian adolescents. BMC Public Health. 2006;6:22.
Patient Preference and Adherence

\section{Publish your work in this journal}

Patient Preference and Adherence is an international, peer-reviewed, open access journal focusing on the growing importance of patient preference and adherence throughout the therapeutic continuum. Patient satisfaction, acceptability, quality of life, compliance, persistence and their role in developing new therapeutic modalities and compounds to

\section{Dovepress}

optimize clinical outcomes for existing disease states are major areas of interest. This journal has been accepted for indexing on PubMed Central. The manuscript management system is completely online and includes a very quick and fair peer-review system. Visit http://www.dovepress.com/ testimonials.php to read real quotes from published authors. 